\title{
New Approach to a Hybrid Fuzzy-Sliding Mode Control to a Brushless AC Motor Scheme
}

\author{
F. Philibert Andriniriniaimalaza \\ Information and Communications Sciences \\ and Technologies Department \\ Higher Polytechnic School \\ Antsiranana, Madagascar
}

\author{
N. Jean Razafinjaka \\ Electrical Engineering Department \\ Higher Polytechnic School \\ Antsiranana, Madagascar
}

\author{
B. Charles Andrianirina \\ Electronic and IT Department \\ Science and Technology's Higher Institute \\ Mahajanga, Madagascar
}

\begin{abstract}
This paper deals with fuzzy-sliding mode control strategies of a Brushless AC Motor. The system combines the performance of fuzzy logic control and sliding mode control. Sliding mode control scheme, fuzzy logic controller strategies and the hybrid fuzzy-sliding mode controller were simulated with Matlab/ Simulink for comparison. Behind this strategy, the main objective is to improve the performance of the fuzzysliding mode control scheme. An experimentation, where all the command were implemented to an MSK23335 Board with a PM50 module and a 90W BLAC Motor is used to validate all the result.
\end{abstract}

Keywords-Brushless Motor, Sliding Mode, Fuzzy Logic, Hybrid controller

\section{INTRODUCTION}

Because of its high performance in front of electromagnetic disturbances, noises and its suitability, Brushless AC motors are used for any safety critical applications [1] such as defense, industries, robotics, etc. It belong to the family of the Permanent Magnet Synchronous Motors. The absence of commutator and brushes help the users to choose more length of the motor for all the applications needed.

The advantages of this motors are: better speed versus torque characteristics, high dynamic response, high efficiency and reliability, long operating life, noiseless operation, higher speed ranges, and reduction of electromagnetic interference (EMI) [2]. His main characteristics is that it is an electrical motor which does not require an electrical connection between stationary and rotating parts, and is categorized based on PMs mounting and the back-EMF shape.

Mathematical modelling gives more comprehension of the system before controlling it. More control strategies are developed but an intelligent controller can provide high accuracy when mathematical model is more complicated [3]. Here, a vector control is proposed, at the first time, to show the effectiveness of the Brushless AC command and control. This strategy is more popular in industrial applications [4].

One type of such controllers is the Sliding Mode Controller which [5] and [6] gives more details about all the possibilities for all applications. But, here, simple Sliding Mode Controller is adopted. Nowadays, fuzzy logic controller strategy was developed and presents more control performance. In this control strategy, some constant parameters are needed to be defined and determined carefully [7], [8].
So, in this paper, an attempt is made to develop a methodology using a Sliding Mode Controller combined with a Fuzzy Logic Controller applied to control a Brushless AC Motor drive. This hybrid controller is developed [9], [10].

After the introduction about the paper, the structure of the proposed system is given. The Brushless AC modeling is shown before applying all the controller. These controllers are: vector control, SMC and FLC. An approach of the hybrid fuzzy-siding mode controller is developed in the next section. The SMC strategy is applied to the BLAC motor for more comprehension of the system. The next one deals with the simulation and experimentation of the proposed methodology through respectively the Matlab and Simulink environment and an MSK development kit [11]. Results and discussions gives more details of the objectives of this study. This report is closed by conclusions.

\section{PROPOSED SYSTEM}

The system, showed by figure Fig. 1, is composed of a DC Sources or an AC/DC converter, the three phase PWM Inverter, the controller and the Brushless Motor.

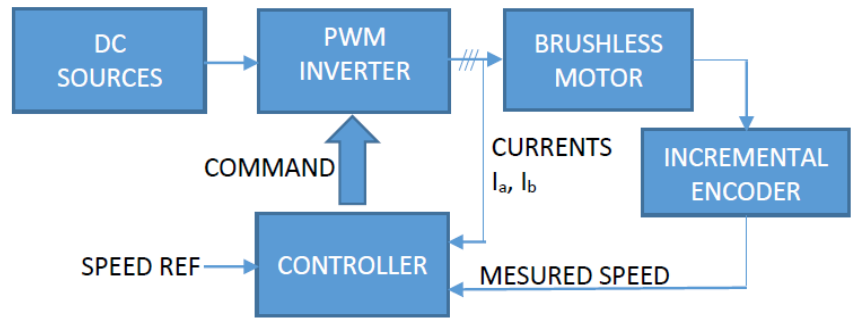

Fig. 1. General scheme of the proposed system

Closed loop control of the brushless motor is used to minimize the presence of parameter variation and load disturbance [3].

\section{Modelling Of The Brushless AC Motor}

A. Electrical equations

A brushless motor [1], [2] can be modeled as,

$$
\left\{\begin{array}{l}
V_{a}=R_{a} i_{a}+\left(L_{a}-M\right) \frac{d i_{a}}{d t}+e_{a} \\
V_{b}=R_{b} i_{b}+\left(L_{b}-M\right) \frac{d i_{b}}{d t}+e_{b} \\
V_{c}=R_{c} i_{c}+\left(L_{c}-M\right) \frac{d i_{c}}{d t}+e_{c}
\end{array}\right.
$$




\section{B. Torque equation}

The electromagnetic torque is expressed as according to currents and flux by:

$$
T_{e m}=\frac{3}{2} p\left[\left(L_{d}-L_{q}\right) i_{d} i_{q}+\phi_{f} i_{q}\right]
$$

\section{Motion equation}

The electromagnetic torque is expressed as according to currents and flux by:

$$
J_{m} \frac{d \Omega}{d t}+f \Omega=T_{e m}-T_{m}
$$

where, $J_{m}$ the total inertia, $f$ the viscous friction coefficient.

\section{Park $d-q$ model for a BLAC Motor}

Then, in the static d-q presentation, a brushless dc motor can be presented by:

$$
\left\{\begin{array}{l}
V_{d}=R_{d} i_{d}+L_{d} \frac{d i_{d}}{d t}-\omega L_{q} i_{q} \\
V_{q}=R_{q} i_{q}+L_{q} \frac{d i_{q}}{d t}+\omega\left(L_{d} i_{d}+\phi_{f}\right)
\end{array}\right.
$$

\section{THE PWM INVERTER}

The Fig. 2 presents the principle of the PWM Sine Triangle on this study.

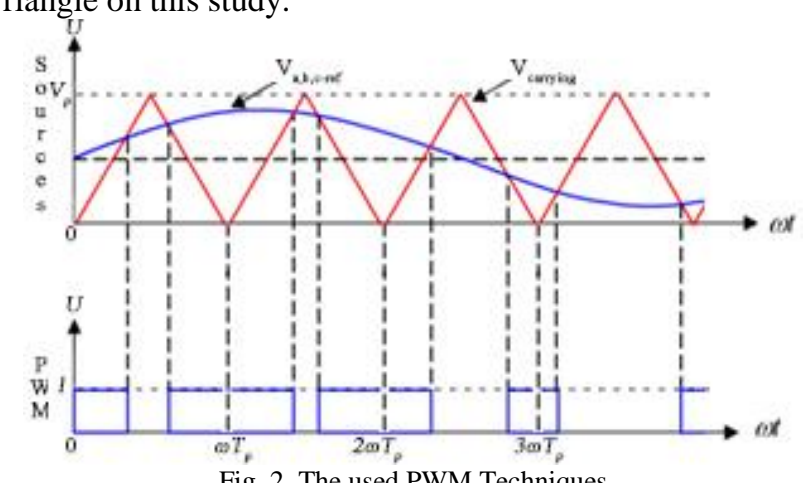

Fig. 2. The used PWM Techniques

The inverter is modeled by:

$$
\left[\begin{array}{l}
V_{a n} \\
V_{b n} \\
V_{c n}
\end{array}\right]=\frac{V_{d c}}{3}\left(\begin{array}{ccc}
2 & -1 & -1 \\
-1 & 2 & -1 \\
-1 & -1 & 2
\end{array}\right)\left[\begin{array}{l}
S_{a} \\
S_{b} \\
S_{c}
\end{array}\right]
$$

\section{CONTROL STRATEGY}

In this part, vector control, sliding mode control, fuzzy logic control and the hybrid controller combined by sliding mode control and fuzzy logic control are presented for more comprehension of control scheme.

\section{A. Vector control}

The more often strategy used consists to maintain the induced reaction flux in quadrature with the rotor flux or replace the magnets by a spool crossed by a current constant If which produces a flux equivalent to the one of the magnets.

$$
\begin{aligned}
& i_{d}=0 \Rightarrow I=i_{q} \\
& \phi_{f}=L_{f} I_{f}
\end{aligned}
$$

The evolution of the couple follows the one of Iq because the flux and the current remained in quadrature. Then, the electromechanical torque is defined by:

$$
T_{e m}=\frac{3}{2} p \phi_{f} I_{q}
$$

In this paper, direct vector control of a brushless ac is adopted. A classical PI controller is given by,

$$
G_{R}(p)=K_{p}+\frac{K_{i}}{p}
$$

\section{B. Sliding Mode Control}

The basic idea of SMC is to bring a system in an area properly selected and then, design a control law to maintain the system in this area [5]. Usually, the SMC goes through three stages as follows:

The general form of the switching surface is given by the equation below [6]:

$$
S(x)=\left(\frac{d}{d t}+\lambda\right)^{n-1} . e
$$

With $\mathrm{e}:$ the error $(\mathrm{Xd}-\mathrm{X}), \lambda$ : the measured signals and $\mathrm{n}$ the order of the system.

The convergence condition is defined by the Lyapunov equation [5]; it is the condition to ensure the area to be attractive and invariant.

$$
S(x) \cdot \dot{S}(x) \leq 0
$$

The algorithm of the control calculation is given by the relation,

$$
u=u_{e q}+u_{n}
$$

Where the control signal is $u$, the equivalent control signal given by $u_{e q}$ and the switching control term $u_{n}$.

The equivalent control signal is calculated with the conditions:

$$
S(x)=0 \Rightarrow \dot{S}(x)=0, u_{n}=0
$$

In the general cases, relation (13) gives the function for the switching control term,

$$
\begin{aligned}
& u_{n}=K \cdot \operatorname{sign}(S(x)) \\
& u_{n}=K \cdot \operatorname{sat}(S(x))
\end{aligned}
$$

In relation (14), a proportional term is added with the first expression of the relation (13). It is made to increase the attraction.

$$
u_{n}=k \cdot \operatorname{sign}(S(x))+k_{1} \cdot S(x)
$$

Where $k$ and $k_{l}$ are constant positive.

\section{Fuzzy Logic Control}

This method avoids modelling the process but having knowledge of its behaviour is required. The reasoning is close to human perception.

Nowadays, the fuzzy controller begins to take an important place in electrical applications. It can be used for optimization and command, [7], [8]. The common scheme for a Fuzzy controller is given in Fig. 3. 


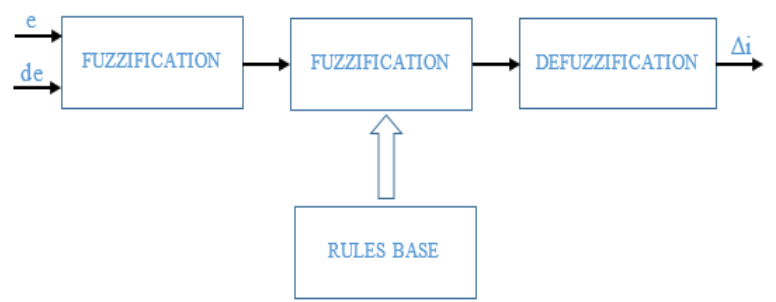

Fig. 3. Structure of a fuzzy controller

With, e: error, de: error variation, di: controller output.

The fuzzification consists in projecting a real physical variable distributed on the domains variable characterizing this variable: linguistic variable is so obtained and then the fuzzification makes it possible to have a precise measurement of the membership degree of the real variable to each fuzzy subset.

Generally, the inference method is a logical operation by which one admits a proposal under the terms of its relation with other proposals held for true. At this stage, rules are established by the knowledge of the desired behavior of the system. They are often as:

Rule k : If ( $x_{1}$ is $\left.A\right)$ AND ( $x_{2}$ is B) THEN $s_{k}=C$

Here, $\mathrm{x} 1$ and $\mathrm{x} 2$ are the inputs and sk the output which is also a linguistic variable. Membership function may be also defined for the output variable. There are several inference methods, which may be applied.

The results of the aggregation of the inference rules still give fuzzy variables. To be used in a real control, these fuzzy variables must be translated into real or numerical variables: it is the function of the defuzzification block. Here, there are also some methods for the defuzzification.

In this paper, the Sugeno's methods are chosen: for the fuzzy inference, a singleton is used as the membership function of the rule consequent combined by the (max-min) method for the rule evaluation. Thus in relation (15), C is a constant. The Sugeno defuzzification is then a weighted average method.

$$
S=\sum \frac{\mu\left(s_{k}\right) \cdot s_{k}}{\mu\left(s_{k}\right)}
$$

For the two inputs (e, de), the triangular and trapezoidal forms are used.

The number of the membership functions of membership $\mathrm{N}=5$ is adopted. For the output, the function of membership of the output is as singleton. Table 1 gives the inference matrix.

The table gives nine rules. For example:

$$
R 1: I F(e=N B) A N D(d E=N B) \text { THEN }(\Delta i=N B)
$$

\begin{tabular}{|c|c|c|c|c|c|c|}
\hline & & \multicolumn{5}{|c|}{$\overline{\mathrm{e}}$} \\
\hline & & $\mathrm{NB}$ & NS & $\mathrm{Z}$ & PS & PB \\
\hline \multirow{5}{*}{ de } & NB & NB & NB & NB & NS & $\mathrm{Z}$ \\
\hline & NS & $\mathrm{NB}$ & $\mathrm{NB}$ & NS & $\mathrm{Z}$ & PS \\
\hline & $\bar{Z}$ & NB & NS & $\mathrm{Z}$ & PS & $\mathrm{PB}$ \\
\hline & PS & NS & $\mathrm{Z}$ & PS & PB & PB \\
\hline & PB & $\mathrm{Z}$ & PS & PB & PB & PB \\
\hline
\end{tabular}

\section{Fuzzy Sliding Mode Control}

This new hybrid controller is a derivative of the scheme proposed in [9], [10]. Here, the switching control term is replaced by a command resulting from fuzzy logic controller (FLC). It is showed by the relation (18):

$$
\left\{\begin{array}{c}
u=u_{e q}+u_{n} \\
u_{n}=u_{F L C}
\end{array}\right.
$$

\section{APPLICATIONS TO THE BRUSHLESS AC MOTOR}

In this part, the controllers below are applied to the speed regulation bloc.

A. SMC applications

$\mathrm{r}=1$ and $\lambda=0$ are adopted for the equation (9). The error is chosen to be the area,

$$
\left\{\begin{array}{c}
S(\Omega)=e(\Omega) \\
S(\Omega)=\Omega_{r e f}-\Omega
\end{array}\right.
$$

Then,

$$
\left\{\begin{array}{c}
\dot{S}(\Omega)=\dot{\Omega}_{r e f}-\dot{\Omega} \\
\dot{\Omega}=\frac{3 p \phi_{f} I_{q}}{2 J_{m}}-\frac{T_{m}}{J_{m}}-\frac{f}{J_{m}} \Omega
\end{array}\right.
$$

During the sliding mode,

$$
S(\Omega)=0 \Rightarrow \dot{S}(\Omega)=0
$$

The reference command of the current is defined by:

$$
I_{\text {qref }}=I_{q e q}+I_{q n}
$$

Then, after applying this to the sliding area, this results:

$$
\begin{aligned}
& I_{q e q}=\frac{2 J}{3 \Phi_{f} p} \dot{\Omega}+\frac{2 T_{m}}{3 \Phi_{f} p}+\frac{2 f}{3 \Phi_{f} p} \Omega \\
& I_{q n}=K_{\Omega} \cdot \operatorname{sign}(S(\Omega))
\end{aligned}
$$

The reference command of the current is expressed by:

$$
I_{\text {qref }}=\frac{2 J}{3 \Phi_{f} p} \dot{\Omega}+\frac{2 T_{m}}{3 \Phi_{f} p}+\frac{2 f}{3 \Phi_{f} p} \Omega+K_{\Omega} \cdot \operatorname{sign}(S(\Omega))
$$

\section{B. The applied Fuzzy Logic}

The Fig. 4 represents the Matlab and Simulink model of the fuzzy logic control bloc from the system.

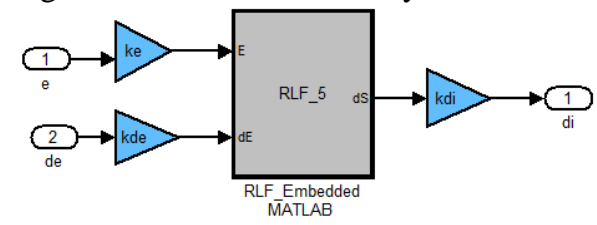

Fig. 4. FLC Model adopted

The error is given by the relation,

$$
e=\Omega_{\text {ref }}-\Omega
$$

which, $\Omega_{\text {ref }}$ is the speed reference and $\Omega$ is the measured speed.

And the variation of the error is given by,

$$
d e=e(n)-e(n-1)
$$

where, e(n) is the new value of the error and $e(n-1)$ is the precedent value.

The last one is $\Delta \mathrm{i}$ represents the reference of the current loop which is represented by $\mathrm{I}_{\text {qref. }}$. 


\section{SimULATION ResUlts}

\section{A. Simulation model}

Matlab Environment is used for the implementation of the brushless dc motor modelling.

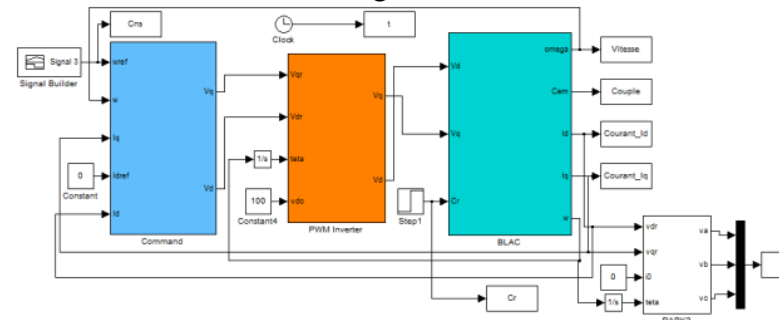

Fig. 5. Model used for simulation in Matlab and Simulink

Vector control, Sliding Mode Control, fuzzy logic control and the hybrid controller are used for evaluating the performance of each control strategy.

\section{B. Simulation results}

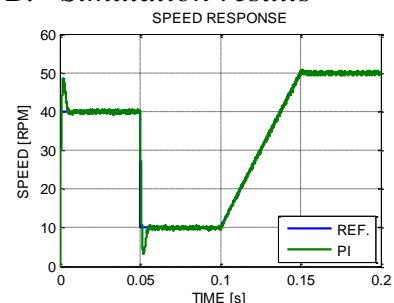

(a)

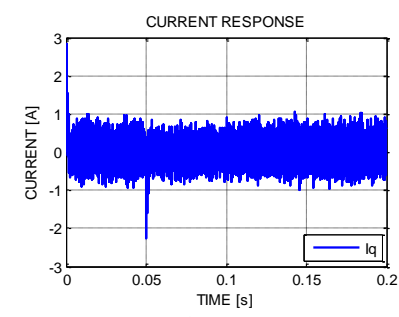

(b)
Fig. 6. Simulation Results with a PI controller, (a): Speed, (b): Current

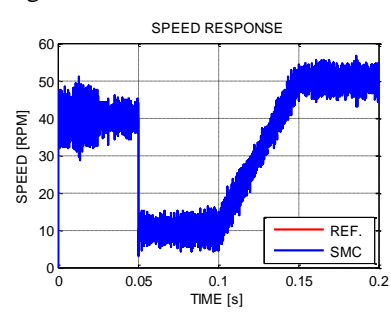

(a)

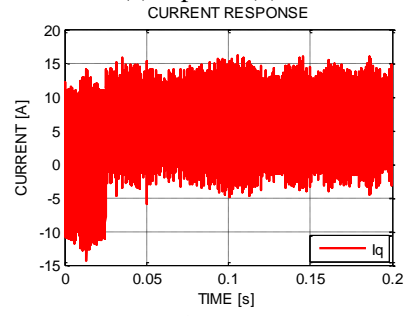

(b)
Fig. 7. Simulation Results with a SMC controller, (a): Speed, (b): Current (a)

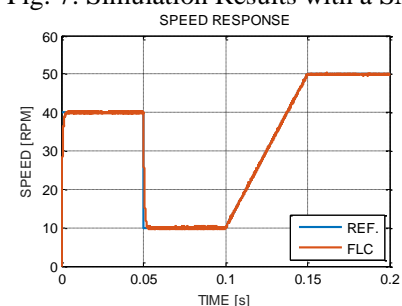

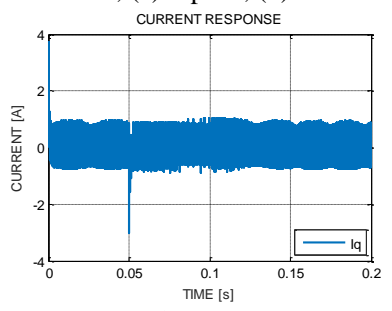

(b)
Fig. 8. Simulation Results with a FLC controller, (a): Speed, (b): Current

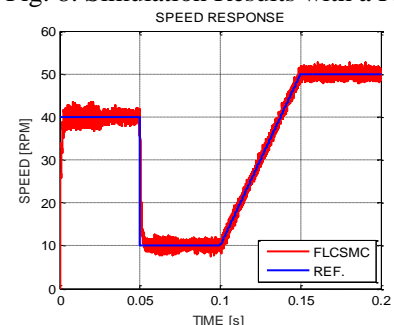

(a)

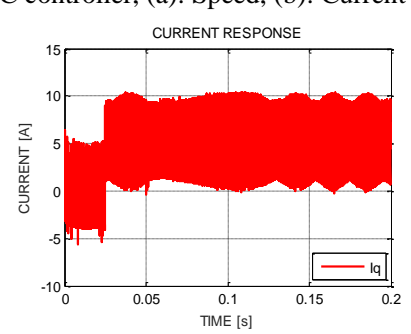

(b)
Fig. 9. Simulation Results with a SMC-FLC controller, (a): Speed, (b): Current

Fig. 6, Fig. 7, Fig. 8 and Fig. 9 show the results of the simulation with all the controllers in Matlab environment. The system combined the robustness of the SM controller with the performance of the FL Controller.

\section{EXPERIMENTAL RESULTS}

\section{A. Experimental platform}

The platform [8] is composed by a MSK23335 board. This

MSK is used for the implementation which all the parts are:

1 , is the DSP controller and the power supply,

2 , is the BLDC motor,

3 , is an intelligent controller for commanding the load effect in a specified time,

4 , is the load (another BLDC motor)

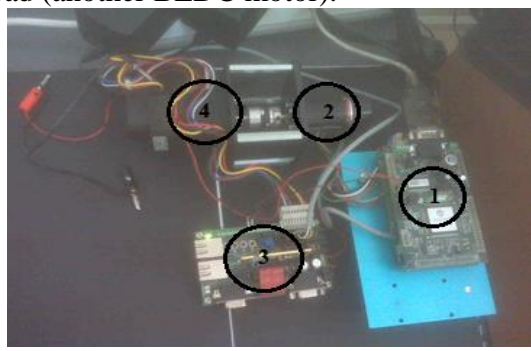

Fig. 10. The development Kit

Experimental results

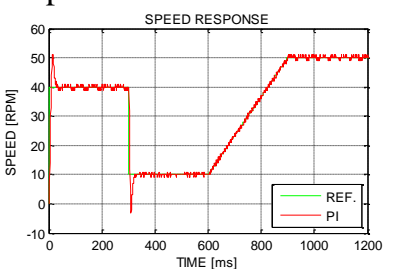

(a)

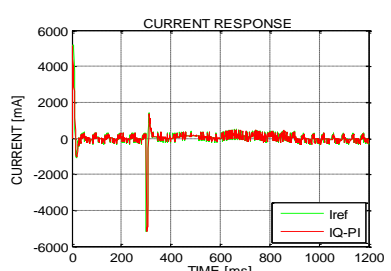

(b)
Fig. 11. Experimental Results with a PI controller, (a): Speed, (b): Current

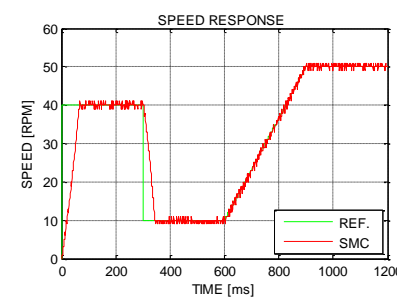

(a)

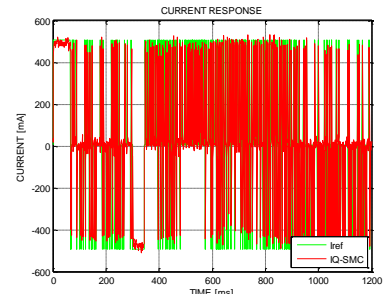

(b)
Fig. 12. Experimental Results with a SMC controller, (a): Speed, (b): Current

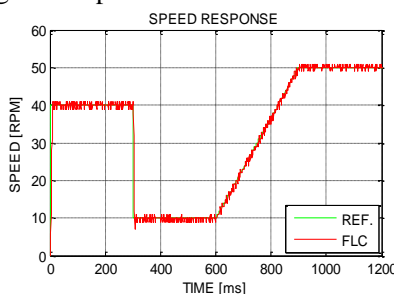

(a)

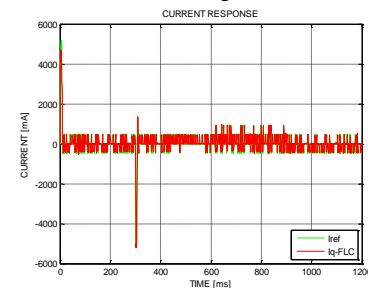

(b)
Fig. 13. Experimental Results with a FLC controller, (a): Speed, (b): Current

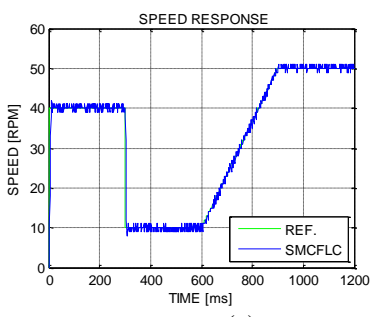

(a)

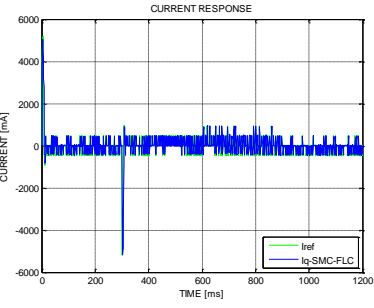

(b)
Fig. 14. Experimental Results with a SMC-FLC controller, (a): Speed, (b): Current 
Fig. 11, Fig. 12, Fig. 13 and Fig. 14 give the experimentation results with all the controllers.

\section{DISCUSSIONS}

A. Simulation results comparison

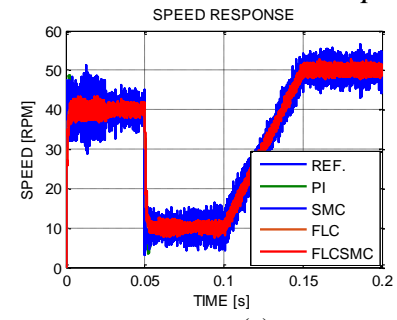

(a)

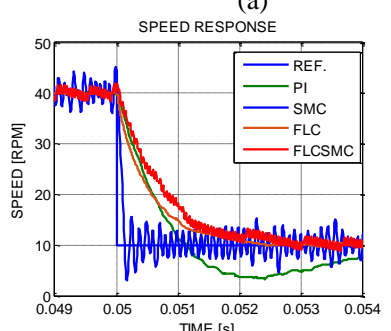

(c)

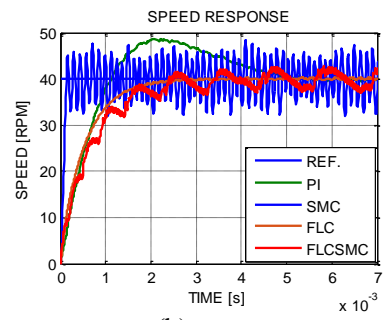

(b)

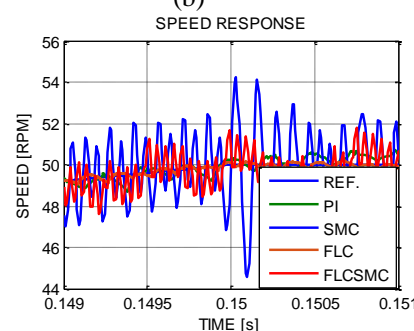

(d)
Fig. 15. Simulation Results of the speed, (a): Comparison, (b): Zoom 1, (c) Zoom 2, (d): Zoom 3

Fig. 15 shows more details about the confirmation below. As shown in (a), all the results are presented. In (b), at the start time, the application of the SMC controller presents more oscillation into the speed results.

And the use of fuzzy-sliding mode control to the system rejects the perturbation and reduces the overshoot into $0 \%$. In (c), at 0.05 [s], the fuzzy-sliding mode control continues to stay away even if the consign is changed to 10 [RPM].

\section{B. Experimental results comparison}

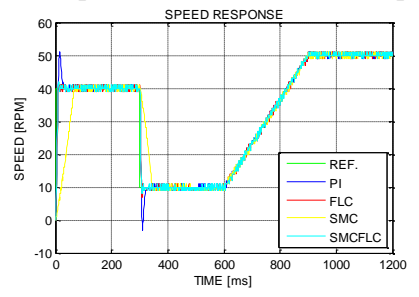

(a)

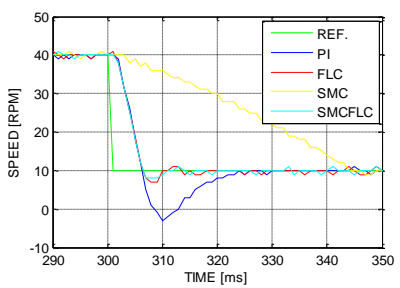

(c)

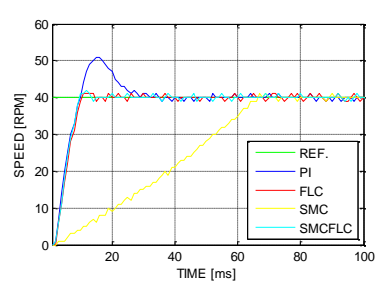

(b)

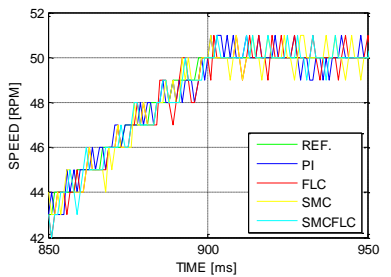

(d)
Fig. 16. Experimental Results of the speed, (a): Comparison, (b): Zoom 1, (c): Zoom 2, (d): Zoom 3

All the experimental results are resumed in Fig. 16 (a). The configuration used here is look like the simulation consign. In (b), the use of a fuzzy-sliding mode control (SMCFLC) gives a conclude result for controlling the system. All the simulation and the experiment results show that the proposed hybrid controllers based on SMC-FLC are realizable and give good performances as disturbance rejection, good behavior in respect of variation parameter.

\section{CONCLUSION}

Vector control, Sliding Mode Control, Fuzzy Logic Control and Fuzzy-sliding mode control are used to control a Brushless AC Motor.

The method based on the hybrid controller is proposed and applied. The result shows the effectiveness and performance of this method. In this paper, it is highlighted that the SMCFLC is the best controller.

APPENDIX

TABLE 2. PARAMETER OF THE BRUSHLESS AC MOTOR

\begin{tabular}{|c|c|c|}
\hline Nominations & Symbols & Values \\
\hline Resistance & $\mathrm{R}$ & $4,3[\mathrm{Ohms}]$ \\
\hline $\begin{array}{c}\text { Electrical } \\
\text { Constant }\end{array}$ & TAU_EL & $82.8 \mathrm{e}-6[\mathrm{~s}]$ \\
\hline Torque Constant & $\mathrm{K}$ & $36.8 \mathrm{e}-3[\mathrm{Nm} / \mathrm{A}]$ \\
\hline Inertia & $\mathrm{J}$ & $11.0 \mathrm{e}-7\left[\mathrm{Kgm}{ }^{2}\right]$ \\
\hline Friction Constant & $\mathrm{F}$ & $0.0[\mathrm{Nms} / \mathrm{rad}]$ \\
\hline Number of lines & $\mathrm{NLines}$ & $500[$ lines/rot $]$ \\
\hline Pair of pole & $\mathrm{p}$ & 1 \\
\hline Power & $\mathrm{P}_{\mathrm{n}}$ & $90[\mathrm{~W}]$ \\
\hline
\end{tabular}

TABLE 3. FUZZY LOGIC PARAMETERS
\begin{tabular}{|c|c|}
\hline Constant & Value \\
\hline ke & $4,2.10 \mathrm{e}^{-4}$ \\
\hline $\mathrm{kde}$ & 0,08 \\
\hline $\mathrm{kdi}$ & 1000 \\
\hline
\end{tabular}

\section{ACKNOWLEDGMENT}

The authors would like to thank Prof. Dr. Ing. Liviu KREINDLER from the University Polithenica of Bucarest, Romania, for allowing the use of the MSK controllers for the experimental facilities.

\section{REFERENCES}

[1] M.M.Kayalvizhi and M.Akilandeswari, Design And Implementation Of Speed Regulator For A PMSM Using Genetic Algorithm, International Journal of Innovative Research in Science, Engineering and Technology An ISO 3297 : 2007 Certified Organization, Volume 3, Special Issue 1, February 2014.

[2] Konrad Urbanski, Position Estimation of the PMSM High Dynamic Drive at Low Speed Range, MATLAB - A Fundamental Tool for Scientific Computing and Engineering Applications - Volume 1, INTECH 2012.

[3] P. Pal, TM Shubhum, and A. Ojha, "Simulation of Brushless DC Motor for Performance Analysis using MATLAB/SIMULINK Environment," International Journal on Recent and Innovation Trends in Computing and Communication. Vol. 2, No. 6, pp. 1564-1567, 2014

[4] Razafinjaka and al., Comparaison des performances des régulateurs PI et IP- Applications aux systèmes fondamentaux, ResearchGate, February 2015.

[5] Utkin, Sliding mode control design- principles and applications to electric drives, IEEE T- Ind. Electron., vol. 40, pp 23-46, 1993.

[6] Razafinjaka and al., Hybrid Controllers Based On Sliding Mode Control For Ac-Dc Converter With Power Factor Correction, in ELECTRIMACS, 2017, 4th -6th July 2017, Toulouse, France.

[7] G. Feng, A Survey on Analysis and Design of Model-Based Fuzzy Control Systems, EEE Transactions on fuzzy systems, vol. 14, NO. 5, October 2006.

[8] Andriniriniaimalaza and al., Parameter Optimization for a fuzzy logic control of a Permanent Magnet Brushless Motor, the 10th International Symposium on Advanced Topics in Electrical Engineering, March 2325, 2017, Bucharest, Romania.

Availlable: https://ieeexplore.iee.org/document/7905123. 
[9] M. Ardjoun, M. Abid, Fuzzy sliding mode control applied to a doubly fed induction generator for wind tirbines, Turkish Journal of Electrical Engineering \& Computer Sciences, pp 1673-1686, 2015.

[10] Kamel Srairi and al., An Hybrid Control Based on Fuzzy Logic and a Second Order Sliding Mode for MPPT in Wind Energy Conversion Systems, International Journal on Electrical Engineering and Informatics, December 2016.

[11] Hamid A. Toliyat, Steven Campbel, « DSP-based Electromechanica Motion Control », Texas A \& M University, Department of Electrical Engineering, College Station, Texas. 